\title{
The Ross sub-coronary technique
}

\author{
Martin Misfeld ${ }^{1,2,3,4,5}$, Christian D. Etz ${ }^{1}$, Michael A. Borger ${ }^{1}$, Hans-H. Sievers ${ }^{6}$ \\ ${ }^{1}$ University Department for Cardiac Surgery, Leipzig Heart Center, Leipzig, Germany; ${ }^{2}$ Department of Cardiothoracic Surgery, Royal Prince Alfred \\ Hospital, Sydney, Australia; ${ }^{3}$ Sydney Medical School, The University of Sydney, Sydney, Australia; ${ }^{4}$ Institute of Academic Surgery, Royal Prince \\ Alfred Hospital and the University of Sydney, Sydney, Australia; ${ }^{5}$ The Baird Institute of Applied Heart and Lung Surgical Research, Sydney, Australia; \\ ${ }^{6}$ Department of Cardiac and Thoracic Vascular Surgery, University Medical Centre Schleswig-Holstein, Campus Lübeck, Lübeck, Germany \\ Correspondence to: Martin Misfeld, MD, PhD. University Department for Cardiac Surgery, Leipzig Heart Center, Strümpellstrasse 39, 04189 Leipzig, \\ Germany. Email: martinmisfeld@yahoo.com.
}

Submitted Aug 31, 2020. Accepted for publication Mar 29, 2021.

doi: 10.21037/acs-2020-rp-184

View this article at: http://dx.doi.org/10.21037/acs-2020-rp-184

\section{Clinical vignette}

A forty-one year old male patient was admitted to our hospital with clinically relevant combined aortic valve disease. Echocardiographic investigations revealed severe aortic valve stenosis of a bicuspid aortic valve with Vmax of $4.3 \mathrm{~m} / \mathrm{s}$, a pressure gradient of $73 / 42 \mathrm{mmHg}$ (max/mean), and an aortic valve area of $0.8 \mathrm{~cm}^{2}$ with left ventricular hypertrophy and normal ejection fraction. Coronary artery disease was excluded.

The patient was scheduled for autologous aortic valve replacement with the sub-coronary technique, initially described by Ross in 1967 (1). This technique was adopted from the modifications performed by Sievers with excellent long-term results (2-5).

\section{Surgical technique}

Following mid-sternotomy, standard aortic cannulation is followed by cannulation of the superior and inferior vena cava for improved venous drainage. The pulmonary artery is marked at the height of later transection. The pulmonary artery and ascending aorta are divided. We prefer intermittent cold blood cardioplegia. The aorta is incised in an oblique or hockey-stick like fashion into the mid non-coronary sinus. If annular diameter is between 26 to $28 \mathrm{~mm}$. We perform a limited annuloplasty by narrowing the left-noncoronary trigone with a pericardial reinforced 3-0 monofilament suture. With this technique, the diameter of the annulus can be reduced by 3 to $4 \mathrm{~mm}$. If the annulus diameter is greater than $32 \mathrm{~mm}$, we do not perform the Ross procedure.

\section{Explantation of the autograft}

The pulmonary artery is completely transected at the previously marked height. The pulmonary valve is inspected and, if there is any macroscopically abnormal findings the Ross procedure is abandoned. A right-angled clamp is passed retrogradely through the pulmonary root, and the right ventricular outflow tract (RVOT) is incised just underneath the nadir of the anterior pulmonary cusps. The RVOT is opened circumferentially with a muscular rim of approximately $4 \mathrm{~mm}$ below the insertion of the pulmonary cusps. Entering the right layer for autograft dissection is of most importance. Care is taken at the first septal coronary branch. This branch is in most cases located near a thick muscle band that is directed towards the pulmonary valve, slightly lateral to the midline of the RVOT. Hemostasis of the bed of the excised autograft is performed.

\section{Implantation of the autograft}

We prefer single interrupted (4-0 polyfiber) sutures for the proximal autograft implantation, with a special implantation technique (a U-shaped suture is followed by three single sutures, followed by a U-suture and so on). We begin in the area of the left- to non-coronary trigone and continue clockwise. When the right- to non-coronary trigone is approached, further sutures are placed now starting in the left- to non-coronary trigone and continuing anticlockwise towards the right- to non-coronary trigone. We usually place the largest pulmonary sinus in the non-coronary sinus of the aortic root, which is often the largest sinus, especially in bicuspid aortic valves type I L/R Sievers classification (6). 
We aim to have a planar implantation line for the proximal sutures. Sutures are passed through the autograft very close to the line of cusp attachment. The autograft is lowered into the left ventricular outflow tract by pulling individually on the sutures. We routinely use a small strip of the prepared pericardium that is incorporated into the proximal suture line not only for hemostasis, but also for annular narrowing and reinforcement. Narrowing of the annulus diameter can be achieved by gentle pulling of the pericardial strip during knot tying.

The commissures of the autograft are inserted well above the native aortic commissures. Care has to be taken not to distort the geometry of the autograft.

The sinuses are resected and the autograft is implanted in a sub-coronary technique in the left- and right sinuses using a 5-0 monofilament suture. The non-coronary sinus of the autograft is preserved and the non-coronary sinus of the native aortic root is closed either directly, after partial resection in case of root dilatation or by incorporating a pericardial patch. The goal is to adjust the size of the native non-coronary sinus to the size of the preserved autograft sinus. Additional 5-0 monofilament $\mathrm{U}$-sutures are used to secure the two non-coronary sinuses to each other. The aorta is finally closed with a 4-0 monofilament suture. If the ascending aorta is enlarged, replacement using a Dacron graft is performed.

\section{Homograft Implantation}

We prefer cryopreserved pulmonary homograft for replacement of the pulmonary valve. Although other valve conduits may be used, data on long-term follow-up are only available for pulmonary homograft $(3,4)$. In adults, we aim to implant homografts with a size of greater than $25 \mathrm{~mm}$. The homograft is also kept longer compared to the harvested pulmonary trunk. The distal suture line is performed with 5-0 and the proximal suture with 4-0 monofilament sutures.

Following left ventricular deairing maneuvers, the crossclamp is released, the patient rewarmed and weaned from cardiopulmonary bypass. Intra-operative transesophageal echocardiogram assesses the operative result. The chest is closed in a standard fashion.

\section{Comments}

The Ross procedure offers excellent long-term results with a high quality of life for selected young patients (2-5).
We prefer the sub-coronary technique in all patients with aortic valve stenosis or combined lesions, as the autograft is protected by the native aortic root. If the annulus is greater than $31 \mathrm{~mm}$ in size or in the presence of a "true" bicuspid aortic valve with only two sinuses, we do not perform this procedure. Additional annular stabilization has been shown to be one key aspect of long-term success. Hereby, results of the authors from his experience in Lübeck and Leipzig are in accordance with the results published by Sievers et al. (5). Precise surgical technique and intra-operative evaluation of the autograft, autograft positioning, annular and sinotubular adjustment, as well as homograft implantation leads to excellent clinical results. The Ross procedure is an excellent additional tool in the armamentarium of treating aortic valve disease, particularly in young patients.

\section{Acknowledgments}

Funding: None.

\section{Footnote}

Conflicts of Interest: The authors have no conflicts of interest to declare.

Open Access Statement: This is an Open Access article distributed in accordance with the Creative Commons Attribution-NonCommercial-NoDerivs 4.0 International License (CC BY-NC-ND 4.0), which permits the noncommercial replication and distribution of the article with the strict proviso that no changes or edits are made and the original work is properly cited (including links to both the formal publication through the relevant DOI and the license). See: https://creativecommons.org/licenses/by-nc-nd/4.0/.

\section{References}

1. Ross DN. Replacement of the aortic and mitral valves with a pulmonary autograft. Lancet 1967;2:956-8.

2. Charitos EI, Hanke T, Stierle U, et al. Autograft reinforcement to preserve autograft function after the ross procedure: a report from the german-dutch ross registry. Circulation 2009;120:S146-54.

3. Richardt D, Hemmer W, Moritz A, et al. Age-related reoperation rate after the Ross procedure: a report from the German Ross Registry. J Heart Valve Dis 2015;24:220-7.

4. Sievers HH, Stierle U, Charitos EI, et al. A multicentre 
evaluation of the autograft procedure for young patients undergoing aortic valve replacement: update on the German Ross Registry. Eur J Cardiothorac Surg 2016;49:212-8.

5. Sievers HH, Stierle U, Petersen $M$, et al. Valve performance classification in 630 subcoronary Ross

Cite this article as: Misfeld M, Etz CD, Borger MA, Sievers HH. The Ross sub-coronary technique. Ann Cardiothorac Surg 2021;10(4):538-540. doi: 10.21037/acs-2020rp-184 patients over 22 years. J Thorac Cardiovasc Surg 2018;156:79-86.e2.

6. Sievers HH, Schmidtke C. A classification system for the bicuspid aortic valve from 304 surgical specimens. J Thorac Cardiovasc Surg 2007;133:1226-33. 